\title{
Seismic Collapse Probability and Life Cycle Cost Assessment of Isolated Structures Subjected to Pounding With Smart Hybrid Isolation System Using a Modified Fuzzy Based Controller
}

\author{
Arash Rayegani \\ Kharazmi University https://orcid.org/0000-0001-7932-7038 \\ Gholamreza Nouri ( $\nabla$ r.nouri@khu.ac.ir) \\ Kharazmi University https://orcid.org/0000-0002-2936-599X
}

\section{Research Article}

Keywords: Smart base isolation control system, Damping system, Collapse probability, Risk assessment, Fragility curve, Incremental dynamic analysis, Near-field, Pounding effect, Fuzzy control system, Genetic algorithm optimization, life cycle cost

Posted Date: January 14th, 2022

DOI: https://doi.org/10.21203/rs.3.rs-1239670/v1

License: (c) (1) This work is licensed under a Creative Commons Attribution 4.0 International License.

Read Full License 
Seismic collapse probability and life cycle cost assessment of isolated structures subjected to pounding with smart hybrid isolation system using a modified fuzzy based controller

\author{
Arash Rayegani, Gholamreza Nouri* \\ Department of Civil Engineering, Faculty of Engineering, Kharazmi University, Tehran
}

*Corresponding author:

Gholamreza Nouri, Department of Civil Engineering, Faculty of Engineering, Kharazmi University, South Mofatteh Avenue, Tehran, 1571914911, Iran

Email: r.nouri@khu.ac.ir 
Seismic collapse probability and life cycle cost assessment of isolated structures subjected to pounding with smart hybrid isolation system using a modified fuzzy based controller

\begin{abstract}
The possibility of pounding on isolated structures with surrounding moat walls is one of the concerns in the design of isolation systems, especially in pulse-type near-field earthquakes. This paper puts forward the seismic probability assessment of structures equipped with passive and smart hybrid isolation systems by considering pounding possibilities. This investigation is performed on isolated structures equipped with a high damper rubber bearing (HDRB) considering stiff moat walls around the structure. In the Hybrid isolation system, magnetorheological dampers (MR) are considered an adaptive dissipation energy device along with isolators using an optimized novel interval Type-2 fuzzy logic controller with adaptive red-zone function (IT2FS+RZF) to reduce pounding possibilities. The fragility curves of the building for various cases are determined using IDA analysis, and possible damage costs are evaluated by using exceedance probability in each damage level. This study concludes that the collapse probability of the isolated structures with restrains at the code-based distance is over the acceptable limit of ASCE 7-22. The smart additional damping system with the proposed controller reduces the possible damage cost of the building by about $64 \%$ compared to the uncontrolled system and puts the collapse probability of the structure in the acceptable range.
\end{abstract}

Keywords: Smart base isolation control system, Damping system, Collapse probability, Risk assessment, Fragility curve, Incremental dynamic analysis, Near-field, Pounding effect, Fuzzy control system, Genetic algorithm optimization, life cycle cost 


\section{Introduction}

The desirable performance of isolated structures requires concentrating lateral displacements at the isolated level and reducing relative displacements of the superstructure. Chapter 17 of ASCE 7-22 (American Society of Civil Engineers, 2021) and older version ASCE 7-16 (American Society of Civil Engineers, 2016) specified the minimum requirements for designing isolated buildings and many projects around the world are designed based on their specifications. The provisions of this standard do not guarantee the prevention of damage to maintain facility function, as it is clearly stated in an executive order by the United States president in 2016 (Hayes Jr et al.). Therefore, it may need to exceed those standards to achieve the desired performance levels to maintain the essential level of building operation. According to this code, the moat clearance distance around the structure must be determined based on the average peak responses of time history analyses at the Risk-Targeted Maximum Considered Earthquake ( $\left.\mathrm{MCE}_{\mathrm{R}}\right)$. It has been shown in various studies that this displacement does not result in an acceptable damage probability for isolated structures with short to mid-rise isolated buildings (Kitayama and Constantinou, 2018; Kitayama and Constantinou, 2019; Shao and Mahin, 2020; Güneş and Ulucan, 2021). In events of near-field earthquakes, especially long-pulse types, due to the particular frequency content and the probability of closing dominant periods of the earthquake to the isolation system periods, large displacements at the isolation level and high damage potential are predictable (Bhandari et al., 2019; Anajafi et al., 2020; Bhagat et al., 2021), which can lead to passing isolated level displacement over code-based gap size. Pounding isolated structures with surrounding moat walls can significantly increase the responses, considering that isolated structures usually have critical facilities, such as hospitals; pounding effects can cause severe human and financial damages. Pant and Wijeyewickrema (2012) showed that the pounding in the isolated structure might cause the building to reach collapse level. Mavronicola et al. (2017) studied the effect of the pounding on isolated structures under bidirectional seismic records and showed that the pounding with moat walls affected structural responses and significantly increased the peak story drift. Sobhi and Far (2021) evaluated the effect of pounding on building behavior by considering soil-structure interaction and proposed an improvement in design criteria.

Increasing the stiffness of isolators to reduce displacement of the isolated level is in conflict with the general philosophy of base isolation and weakens the expected performance of the isolation system. A common way to reduce the displacement of the isolation level is using an additional damping system along with the isolators, which can increase the seismic response of the superstructure (Providakis, 2008). Passive dampers are typically designed for severe earthquakes such as near-field events. However, under small and moderate earthquakes, they may increase responses of the structure by imposing excessive forces on the structure. Wolff et al. (2015) examined the effects of linear and nonlinear viscous dampers with a specific damping coefficient on the behavior of the isolated structures using experimental and analytical results. Their results showed that the additional damping system in the isolation system might increase seismic responses of the superstructure depending on the isolation system's damping. Providakis (2008) 
examined viscous dampers with three different damping coefficients under near-field and far-field earthquakes at the isolated level. He concluded that, unlike near-field earthquakes, an increase in the damping coefficient of a damper under far-field earthquakes would lead to an increase in the superstructure's seismic responses. In contrast to passive control systems, smart dampers are able to adjust their behavioral specifications to those of the earthquakes and structures based on their controller systems (Chan et al., 2019).

From this perspective, using smart damping control systems to enhance the reliability of the isolated buildings that are likely to pound with surrounding obstacles is highly recommended, which is poorly addressed in the literature. Most research in this area focuses on pounding effects on isolated buildings without additional damping systems or with passive dampers at the isolation level, although there are some limited works on assessing the ability of smart dampers to reduce pounding effects.

Sheikh et al. (2012) used magnetorheological (MR) dampers to reduce the pounding effect on the bridge parts by using a simple controller. Shrimali et al. (2015) coupled two adjacent isolated and fixed base buildings with MR damper at floor elevations to control pounding and responses for the case of using a sliding isolation system. In another study, Dumne et al. (2017) evaluated these buildings in the case of using elastomeric bearings. El-Khoury et al. (2018) mitigated the pounding effect of bridge pounding by using an MR damper and clipped sliding mode controller. Mazza and Labernarda (2020) connected the fixed-base elevator shaft to the isolated building using the magnetic damped link to reduce the pounding effect. Rayegani and Nouri (2020) evaluated the application of MR dampers along with rubber bearings to prevent pounding in isolated structures by considering different gap sizes and using Type-1 fuzzy logic controller under pulse-type earthquakes.

Most studies in the field of smart damper controller systems have been on Type-1 fuzzy logic controller that has constant membership functions. Type-2 fuzzy control systems include membership functions with intervals that cover potential uncertainties of earthquakes and structural component properties. Bathaei et al. (2018) evaluated the performance of combined TMD with MR dampers using a Type-2 fuzzy logic controller located at the top floor of an 11degree freedom building. They showed that Type- 2 fuzzy controller could reduce further responses compared to the Type-1 fuzzy controller. In addition, in the case of isolated structures that are likely to be pounded, considering the penalty term can reduce the risk of the structure colliding.

In this study, the Type-2 fuzzy-based controller system is developed by the Red-Zone function as a decision-maker beside the fuzzy controller to improve controller ability to prevent possible pounding, and the gap distance is considered according to the ASCE 7-22 standard. The fragility curves of the building of studied cases are estimated using IDA analysis, and the collapse probability and damage costs of models are evaluated and compared for passive and semi-active hybrid isolation with different control strategies. The particular objectives of the study are 1assessing pounding effect on the isolated structure under near-field earthquakes; 2-evaluating the 
probability exceedance of isolated structure with moat wall under near-field earthquakes; 3evaluating the efficiency of the novel controller to enhance the reliability of isolated structure with moat walls in compare to others investigated controller systems; 4- carrying out life cycle damage cost analysis for considered cases.

\section{Building model and Analytical methodology}

In this study, a (3D) 4-story building model with a story height of $3.2 \mathrm{~m}$ and a special steel moment frame system, as the lateral load resisting system, is investigated (Rayegani and Nouri, 2020). The building has two six-meter spans in the longitudinal direction and one eight-meter span in its perpendicular direction. The isolators are located below the ground floor, and the MR damper is located at the center of the diaphragm. Dead and live loads applied to this building are $5 \mathrm{kN} / \mathrm{m} 2$ and $2.5 \mathrm{kN} / \mathrm{m} 2$, respectively. The building is designed without considering the effects of dampers in accordance with AISC360-16 (ANSI, 2016) and ASCE 7-22 standard specifications. It is considered that the building is located on soil type $\mathrm{C}$ and an area with the risk category of type 3 . The $S_{M S}$ and $S_{M 1}$ of the $M_{C E R}$ spectrum used for the design of the superstructure are equal to $1.07 \mathrm{~g}$ and $1.36 \mathrm{~g}$, respectively. The modification coefficient $\left(\mathrm{R}_{\mathrm{I}}\right)$ is considered 2. Six similar HDRB isolators are located under the columns with the diameter and rubber height of $700 \mathrm{~mm}$ and 200 $\mathrm{mm}$, respectively. The shear modulus of the isolators is $0.62 \mathrm{MPa}$. The vertical stiffness of the isolators and their equivalent lateral stiffness at $100 \%$ strain are $2660 \times 10^{3} \mathrm{kN} / \mathrm{m}$ and $1180 \mathrm{kN} / \mathrm{m}$, respectively. The beam sections are $\mathrm{W} 21 \times 93$ and $\mathrm{W} 21 \times 122$ in long and short spans, respectively. The lower two floors have the column section of $\mathrm{W} 14 \times 176$, and $\mathrm{W} 14 \times 145$ section is used in the upper two floors.

The OpenSees software (McKenna et al., 2006) is used to perform nonlinear time history analysis. The behavior of the beam and column elements is modeled nonlinearly along with the elements. High damping rubber bearings are modeled using the model proposed by Kikuchi et al. (2012). MR damper's behavior is modeled in MATLAB (2015) software using the Bouc-Wen model, which is described in detail in the next section. The damper force at each time step of the analysis is applied to the model by using a network between OpenSees and MATLAB. Moreover, for considering pounding in the analysis, Hertz contact elements with the stiffness of $5 \times 10^{6} \mathrm{kN} / \mathrm{M}$ are modeled at the location of columns, which are shown with red lines in Figure 11.

According to ASCE 7-22 isolators shall have minimum displacement capacity equal to total maximum displacement $\left(D_{T M}\right)$. The $D_{T M}$ included actual and accidental torsion shall not be taken less than that calculated from $\mathrm{Eq}(2)$ or 1.15 time of maximum isolators' displacement $\left(\mathrm{D}_{\mathrm{M}}\right)$. The $\mathrm{D}_{\mathrm{M}}$ can be calculated from Eq. (1) at the MCE hazard level. Herein, the nominal properties of isolators are considered to calculate the maximum displacement of isolators.

$D_{M}=\frac{g S_{M 1} T_{M}}{4 \pi B_{M}}$ 
$D_{T M}=D_{M}\left[1+y \frac{12 e}{b^{2}+d^{2}}\right]$

In these equations, $B_{M}$ is a damping coefficient of the isolation system; $S_{M 1}$ is spectral Acceleration at MCE hazard level and period of $1 \mathrm{~s}$; e is the total eccentricity; $\mathrm{b}$ and $\mathrm{d}$ are the dimensions of the structure plan at isolated level. The standard allows reduction of required displacement up to $0.8 D_{T M}$ provided that the time history analysis is performed. By considering that the value of $D_{T M}$ is about $330 \mathrm{~mm}$; in two cases, the distance of moat walls is assumed to be $330 \mathrm{~mm}$ and $264 \mathrm{~mm}$ from the outer edges of the building.

\section{Ground motion selection and probability analysis}

Near-field earthquakes with large velocity pulses may significantly affect the performance of the isolated buildings due to the proximity of the dominant pulse period to the isolated system. Therefore ten long-pulse earthquake records are used in probability analysis assessment. Table 1 lists the properties of these records, which have also been introduced by FEMA P695 (Council, 2009).

Table 1. Records properties near-field pulse-like earthquake records

\begin{tabular}{cccccc}
\hline NO. & $\begin{array}{c}\text { NGA } \\
\text { no. }\end{array}$ & Event & Magnitude & Station Name & Year \\
\hline 1 & 181 & Imperial_Valley-06 & 6.5 & El_Centro_Array_\#6 & 1979 \\
2 & 182 & Imperial_Valley-06 & 6.5 & El_Centro_Array_\#7 & 1979 \\
3 & 292 & Irpinia-Italy-01 & 6.9 & Sturno & 1980 \\
4 & 723 & Superstition_Hills-02 & 6.5 & Parachute_Test_Site & 1987 \\
5 & 802 & Loma_Prieta & 7.6 & Saratoga-Aloha_Ave & 1989 \\
6 & 821 & Erzican-Turkey & 6.7 & Erzincan & 1992 \\
7 & 1063 & Northridge-01 & 6.7 & Rinaldi_Receiving_Sta & 1994 \\
8 & 1086 & Northridge-01 & 6.7 & Sylmar-Olive & 1994 \\
9 & 1503 & Chi-Chi-Taiwan & 7.6 & TCU065 & 1999 \\
10 & 1605 & Duzce-Turkey & 7.1 & Duzce & 1999 \\
\hline
\end{tabular}

The fragility analysis is an effective tool in the risk assessment of the structures, which provides the exceeding probability for specified damage levels (Shirazian et al., 2011; Alam et al., 2012; Massumi et al., 2021). In this regard, the exceeding probability of structure is assessed using IDA analysis to develop fragility curves for different demand measures. The expanded form of IDA analysis was firstly introduced by Vamvatsikos and Cornell (2002) and applied in many studies (Rayegani, 2014). In IDA, the structure is analyzed under seismic ensemble records scaled by a range of constant scale factors. Here, the PGA of selected records is scaled from $0.1 \mathrm{~g}$ to $0.6 \mathrm{~g}$ with an interval of $0.1 \mathrm{~g}$. The fragility can be stated by a lognormal probability distribution function as shown in Eq (3). 
$P\left[D S_{i} / I M\right]=\varphi\left[\frac{1}{\beta_{D S}} \ln \left(\frac{I M}{I M_{\mathrm{DS}}}\right)\right]$

Where $I M$ is a selected intensity measure of structure responses; $I M_{D S}$ and $\beta_{D S}$ are the median value and standard deviation of intensity measure, at which building reaches the desired damage state limit $\left(D S_{i}\right) ; \varphi$ is termed as the standard normal cumulative distribution function (Ellingwood and Kinali, 2009). The standard deviation in Eq (3) expresses total variability related to the seismic demand and structure capacity. The uncertainty in the structural capacity is assumed to equal 0.3 (Mansouri et al., 2017), and the uncertainty in demand is calculated by the standard error in regression analysis. The response of the building can be expressed by lognormal distribution with the following equation.

$\ln (D S)=\ln (a)+b \ln (I M)$

Where $a$, and $b$ are constant values obtained by performing the regression analysis.

\section{Semi-active dissipation energy device}

Smart control systems generally are divided into two categories of semi-active and active control devices (Khansefid and Bakhshi, 2019). Semi-active systems are desirable due to no need for a significant external source of energy and no risk of instability due to error in the input forces. Here, the MR damper is used as a semi-active control system along with isolators to control the displacement of the isolated level. Various models have been proposed to model the behavior of MR dampers, and in this study, the Bouc-Wen model has been used due to its capability of modeling the damper behavior at different voltages. This model has a great capacity to model nonlinear behavior and has been widely used in previous studies (Ismail et al., 2009). In Figure 1, a schematic view of this model, which consists of a viscose element, a linear spring, and a BoucWen element, is illustrated. The equation governing this model is as follows:

$f_{M R}\left(\dot{x}, z_{M R}\right)=c_{0} \dot{x}+k_{0} x+\alpha z_{M R}+f_{0}$

$\dot{z}_{M R}=-\gamma z_{M R}|\dot{x}|\left|z_{M R}\right|^{n-1}-\beta \dot{x}\left|z_{M R}\right|^{n}+A_{m} \dot{x}$

Where the variables $\gamma, \beta, n$, and $A_{m}$ are constant values and determined based on experimental results. $z_{M R}$ and $\dot{x}$ are the evolutionary variable and the velocity of the damper, respectively. In order to obtain the behavior of the damper based on the input control voltage, the values of $c_{0}, k_{0}$, and $\alpha_{0}$ are assumed to be dependent on the command voltage $(u)$ according to equations (7) to (9).

$$
\begin{aligned}
& \alpha_{0}=\alpha_{a}+\alpha_{b} u \\
& c_{0}=c_{a}+c_{b} u \\
& k_{0}=k_{a}+k_{b} u
\end{aligned}
$$


The experimental results performed on MR dampers by Yang et al. (2004) are implemented to obtain constant and dependent parameters $\left(\alpha_{a}, \alpha_{b}, c_{a}, c_{b}, k_{a}\right.$, and $\left.k_{b}\right)$ of the Bouc-Wen model using the genetic algorithm, and are reported in Table 2 (Rayegani and Nouri, 2020).

Table 2. Optimized parameters of Bouc-Wen

\begin{tabular}{cccccc}
\hline Parameter & Value & Parameter & Value & Parameter & Value \\
\hline$\alpha_{a}$ & $122(\mathrm{kN} / \mathrm{m})$ & $k_{a}$ & $6.7(\mathrm{kN} / \mathrm{m})$ & $\beta$ & $83 \mathrm{~m}^{-2}$ \\
$\alpha_{b}$ & $1482(\mathrm{kN} / \mathrm{m} / \mathrm{v})$ & $k_{b}$ & $9.5(\mathrm{kN} / \mathrm{m} / \mathrm{v})$ & $\gamma$ & $25493 \mathrm{~m}^{-2}$ \\
$c_{a}$ & $51(\mathrm{kN} . \mathrm{s} / \mathrm{m})$ & $A_{m}$ & 74 & $f_{0}$ & $-161 \mathrm{~N}$ \\
$c_{b}$ & $387(\mathrm{kN} . \mathrm{s} / \mathrm{m} / \mathrm{v})$ & $n$ & 1.96 & & \\
\hline
\end{tabular}

As shown in Figure 2-a, the Bouc-Wen model with optimized parameters properly models the behavior of the damper at voltage $2 \mathrm{~V}$, and there is only a small difference in force roll-off zone in the low-velocity region. Figure 2-b shows the modeled force of the damper at different voltages.

\section{Modified Type-2 fuzzy controller}

The specifications of the viscose material inside the MR dampers change by input command voltages from controller systems. For achieving the optimal performance of the smart control system, the input voltage to the MR damper must be determined by a real-time control algorithm based on the status of the structure during an earthquake. Common control algorithms require complex and precise mathematical models in accordance with the specifications of the structure for decision making. Due to the fact that creating mathematical models of a building has many complexities and the specifications may change during an earthquake, the application of fuzzy logic theory as a control system has been of interest in many previous studies (Choi et al., 2004; Yan et al., 2020). In most studies, the Type-1 FLC system has been used as a controller, while Type-2 fuzzy logic systems are a complete form of the typical Type- 1 controller. The weakness of this type of MF is its inability to cover uncertainties related to inputs due to the constant membership. For overcoming this deficiency, the membership functions of Type-2 fuzzy logic are composed of two lower and upper bounds, and the area between the bounds is called the footprint of uncertainty (FOU). In addition, the output process of Type-2 fuzzy logic has a type-reducer in addition to the Type-1 fuzzy system (Shariatmadar et al., 2014).

\subsection{Red-zone function}

In this paper, an adaptive Red-zone function $\left(R_{u}(t)\right)$ is combined with the interval Type-2 FLC system to improve the ability of the control system to reduce the possibility of pounding at different hazard levels. This function directly increases the force of MR dampers based on velocity and gap distance between the structure and moat walls. The terms of this function are expressed in $\mathrm{Eq}(10)$ : 
$R_{u}(t)=1+\rho\left(u_{x}^{2}+\beta(u)\right)$

$\rho=\frac{(\operatorname{sign}(i u)+1)}{2}$

Where, $u$ and $\dot{u}$ are displacement and velocity of isolated level, respectively; $\beta(u)$ is defined in Eq. (12)

$$
\beta(\mathrm{u})=\left\{\begin{array}{lr}
-\mathrm{U}_{R}^{+2} & u \geq \mathrm{U}_{R}^{+} \\
-u_{x}^{2} & \mathrm{U}_{R}^{-} \leq u \leq \mathrm{U}_{R}^{+} \\
-\mathrm{U}_{R}^{-2} & u \leq \mathrm{U}_{R}^{-}
\end{array}\right.
$$

The value of the $\mathrm{U}_{R}$ defined equal to $0.6 \mathrm{D}_{\mathrm{TM}}$ based on results obtained from try and error analysis. In this regard, $40 \%$ of the total capacity of the isolators is considered as Red zone length, and if the structure reaches this area, the command voltages will be multiplied by the coefficient of the Red-zone function that is shown in Figure 3. The schematic diagram of IT1FS and IT2FS+RZF systems are shown in Figures 4 and 5, respectively.

\subsection{Optimization of fuzzy control system}

Determining the relation between superstructure responses and the damper command voltages is a difficult procedure by trial and error or conventional design approach, especially in the case of the existence possibility of pounding. In this regard, the integrated GA-FLC system is developed to derive optimal properties of MF. The Genetic algorithm is a popular optimization method that finds succeeding particles using natural evolution methods such as crossover, mutation, and reproduction (Ehrgott, 2008). After several preliminary studies, the velocity and displacement of the isolation level are used as decision variables in the fuzzy inference system to determine the MR damper's command voltage. In the optimization process, the properties of the membership functions are considered variables while the symmetry is maintained. The GA is performed with the aim of minimizing the sum of maximum drift and acceleration under ten considered earthquakes scaled to MCE level. The abbreviations of the membership functions for input and output are given in Tables 3 and 4 .

Table 3. Fuzzy variable for inputs values (velocity and displacement)

\begin{tabular}{ll}
\hline Linguistic variable & Definition \\
\hline NL & Negative Large \\
NM & Negative Medium \\
NS & Negative Small \\
Z & Zero \\
PS & Positive Small \\
PM & Positive Medium
\end{tabular}




\begin{tabular}{ll} 
PL & Positive Large \\
\hline
\end{tabular}

Table 4. Fuzzy variable for output values (Voltage)

\begin{tabular}{ll}
\hline Linguistic variable & Definition \\
\hline VL & Very Large \\
L & Large \\
M & Medium \\
S & Small \\
Z & Zero \\
\hline
\end{tabular}

The rules governing the fuzzy logic are based on empirical vision and trial and error analysis as described in Table 5; moreover, they are considered constant in the process of optimization. The optimized specification of the membership function for displacement and velocity as input variables are shown in Figures 6 and 7 for command voltage in Figure 8.

Table 5. Fuzzy control rules

\begin{tabular}{|c|c|c|c|c|c|}
\hline \multirow[t]{2}{*}{$\begin{array}{l}\text { Velocity at } \\
\text { isolated level }\end{array}$} & \multicolumn{5}{|c|}{$\begin{array}{c}\text { Displacement at isolated } \\
\text { level }\end{array}$} \\
\hline & $\overline{\mathrm{NL}}$ & NM & $\mathrm{Z}$ & $\mathrm{PM}$ & PL \\
\hline NL & VL & $\mathrm{L}$ & $\mathrm{M}$ & $\mathrm{S}$ & $\mathrm{S}$ \\
\hline NM & VL & $\mathrm{L}$ & $S$ & $\mathrm{M}$ & $\mathrm{M}$ \\
\hline NS & $\mathrm{L}$ & Z & $\mathrm{Z}$ & Z & $\mathrm{L}$ \\
\hline PS & L & Z & Z & Z & $\mathrm{L}$ \\
\hline PM & $\mathrm{M}$ & $\mathrm{M}$ & $S$ & $\mathrm{~L}$ & VL \\
\hline PL & $\mathrm{S}$ & $\mathrm{S}$ & M & $\mathrm{L}$ & VL \\
\hline
\end{tabular}

The lower and upper bounds with related FOU area of Type2 FLC for input membership functions are depicted in Figure 9.

\section{Life Cycle Cost (LCC)}

In evaluating the seismic performance of a structure, one of the most effective assessment tools for considering probable damages in the future due to the occurrence of earthquakes during the lifetime of a structure originates in the damage cost. In recent years, various methods have been introduced to estimate the possible seismic damage of buildings. Wen and Kang (2001) developed a design criteria approach for a nine-story building based on Life Cycle Cost (LCC). Castaldo et al. (2016) used an LCC assessment for an isolated structure with friction pendulum isolators by adopting a probabilistic framework. NourEldin et al. (2019) evaluated the performance of a hybrid damper by generating fragility curves and calculating LCC.

The probable damage cost of a structure, $C_{L s, i}$, refers to the cost of repair plus the direct and indirect costs when the building is out of service due to an earthquake during the lifetime period of new or existing structures. The maximum drift of the stories (from now on called "Drift") is a 
suitable measure for estimating the structural damages and is used in many studies to predict the damage level. On the other hand, the maximum floor acceleration (from now on called "Acceleration") is used to estimate non-structural damages, including damage to the internal equipment of the structure. Using the relationships provided by Wen and Kang (2001) and Elenas and Meskouris (2001), the damage levels of the structure are estimated at seven failure levels classified in Table 6.

Table 6. Performance limit state of building according to the structural responses

\begin{tabular}{cccc}
\hline $\begin{array}{c}\text { Performance } \\
\text { level }\end{array}$ & $\begin{array}{c}\text { Damage } \\
\text { state }\end{array}$ & Drift $(\%)$ & Acceleration (g) \\
\hline 1 & None & $\Delta \leq 0.2$ & $\mathrm{~A} \leq 0.1$ \\
2 & Slight & $0.2<\Delta \leq 0.5$ & $0.1<\mathrm{a} \leq 0.2$ \\
3 & Light & $0.5<\Delta \leq 0.7$ & $0.2<\mathrm{a} \leq 0.4$ \\
4 & Moderate & $0.7<\Delta \leq 1.5$ & $0.4<\mathrm{a} \leq 0.80$ \\
5 & Heavy & $1.5<\Delta \leq 2.5$ & $0.80<\mathrm{a} \leq 1.02$ \\
6 & Major & $2.5<\Delta \leq 5$ & $1.02<\mathrm{a} \leq 1.25$ \\
7 & Destroyed & $\Delta>5$ & $\mathrm{~A}>1.25$ \\
\hline
\end{tabular}

Generally, the total damage cost of structures for each limit state $\mathrm{C}_{\mathrm{Ls}, \mathrm{i}}$ includes the cost of different damage types as calculated by equation (13) (Mitropoulou et al., 2011).

$$
C_{L s, i}=C_{d a m}+C_{c o n, i}^{\Delta}+C_{c o n, i}^{a c c}+C_{r e n}+C_{i n c}+C_{i n j}+C_{f a t}
$$

The average damage cost values per area unit are obtained from (Castaldo et al., 2016), and the related coefficient of each damage type is calculated according to the FEMA 227 (Agency., 1992) and ATC-13 standards (Council, 1985) and shown in Figure 10.

\section{Analysis and results}

\subsection{Assessment of Pounding effect}

The isolated structure without additional damping systems is initially evaluated by considering two different distances for the moat walls under selected seismic records. In the case that the moat wall distance is according to the ASCE07-22 (1.0D median and $84 \%$ of Drift and Acceleration for with and without moat walls are shown in Figure 11. In the case of $1.0 \mathrm{D}_{\mathrm{TM}}$, the mean and $84 \%$ values of drift increased by about $5 \%$ and $11 \%$ on average, and in the case of $0.8 \mathrm{D}_{\mathrm{TM}}$, the mean and $84 \%$ values increased by $89 \%$ and $80 \%$, respectively. The effect of pounding on Acceleration has been much more significant, and in the case of $1.0 \mathrm{D}_{\mathrm{TM}}$, mean and $84 \%$ values of floor acceleration result in a $15 \%$ and $23 \%$ increase averagely. In Case $0.8 \mathrm{D}_{\mathrm{TM}}$, this increase is about 3.4 and 2.7 times, respectively. In this case, $84 \%$ value of floor acceleration increased about six times at the base level. 


\subsection{Probability assessment and damage cost analysis}

The resistance force of the MR damper can be justified to control the displacement of the isolated level without adversely affecting the performance of the superstructure. The displacement and velocity-time histories at the isolation level, the input voltage of the damper obtained from the fuzzy surface for each time step, and the MR damper force for Northridge (NGA = 1063) earthquake events scaled to the MCE hazard level are shown in Figure 12.

The achieved data of structure responses from IDA analysis is used to develop the probability seismic demand model (PSDM) by performing regression analysis. Figure 13 illustrates the PSDM of structure Drift for the case of 1.0D according to Eq. (4) for considered demand measures and models.

Table 7. PSDMs for considered models and demand measures

\begin{tabular}{|c|c|c|}
\hline $\mathrm{DM}$ & Control strategy & PSDM \\
\hline \multirow[t]{5}{*}{ Drift } & $1.0 \mathrm{D}_{\mathrm{TM}}-\mathrm{WO}$ damper & $\ln (0.229)+2.32 \ln (\mathrm{PGA})$ \\
\hline & $0.8 \mathrm{D}_{\mathrm{TM}}-\mathrm{WO}$ damper & $\ln (3.67)+4.32 \ln (\mathrm{PGA})$ \\
\hline & $0.8 \mathrm{D}_{\mathrm{TM}}$-Passive & $\ln (0.248)+2.60 \ln (\mathrm{PGA})$ \\
\hline & $0.8 \mathrm{D}_{\mathrm{TM}} \mathrm{IT} 1 \mathrm{FS}$ & $\ln (0.173)+2.59 \ln (\mathrm{PGA})$ \\
\hline & $0.8 \mathrm{D}_{\mathrm{TM}}-\mathrm{IT} 2 \mathrm{FS}+\mathrm{RZF}$ & $\ln (0.154)+2.61 \ln (\mathrm{PGA})$ \\
\hline \multirow[t]{5}{*}{ Acceleration } & $1.0 \mathrm{D}_{\mathrm{TM}^{-}} \mathrm{WO}$ damper & $\ln (2.01)+0.741 \ln (\mathrm{PGA})$ \\
\hline & $0.8 \mathrm{D}_{\mathrm{TM}}-\mathrm{WO}$ damper & $\ln (4.92)+1.27 \ln (\mathrm{PGA})$ \\
\hline & $0.8 \mathrm{D}_{\mathrm{TM}}$-Passive & $\ln (2.08)+0.73 \ln (\mathrm{PGA})$ \\
\hline & $0.8 \mathrm{D}_{\mathrm{TM}^{-}} \mathrm{IT} 1 \mathrm{FS}$ & $\ln (1.69)+0.69 \ln (\mathrm{PGA})$ \\
\hline & $0.8 \mathrm{D}_{\mathrm{TM}}-\mathrm{IT} 2 \mathrm{FS}+\mathrm{RZF}$ & $\ln (1.56)+0.65 \ln (\mathrm{PGA})$ \\
\hline
\end{tabular}

In the assessment of the collapse probability, the deterministic threshold of the limit state should be specified. The exceedance probabilities values for Drift and Acceleration are compared at moderate and collapse damage states. The limit state for collapse and moderate states respectively are assumed equal to $5 \%, 1.2 \%$ for drift, and $1.25 \mathrm{~g}, 0.8 \mathrm{~g}$ for Acceleration according to the design standards and engineering judgments (FEMA, 2003; Alam et al., 2012; Gong and Xiong, 2016). Table 7 describes the characteristics of fragility curves, such as the median and deviation of various scenarios. The related fragility curves are shown in Figures 14 and 15. In these figures, the horizontal axis is relative to the MCE spectrum intensity at the main period of the isolated structure, such that the scale factor of 1 shows the MCE level at the main period of the structure.

Table 8. specifications of fragility curves for considered damage states 


\begin{tabular}{|c|c|c|c|c|c|}
\hline \multirow{3}{*}{ DM } & \multirow{3}{*}{ Control strategy } & \multicolumn{4}{|c|}{ Damage states } \\
\hline & & \multicolumn{2}{|c|}{ Moderate } & \multicolumn{2}{|c|}{ Collapse } \\
\hline & & $\begin{array}{c}\text { Median } \\
(\mathrm{g})\end{array}$ & $\beta_{D S}$ & $\begin{array}{c}\text { Median } \\
(\mathrm{g})\end{array}$ & $\beta_{D S}$ \\
\hline \multirow[t]{5}{*}{ Drift } & $1.0 \mathrm{D}_{\mathrm{TM}^{-}}-\mathrm{WO}$ damper & 0.31 & 0.46 & 0.52 & 0.46 \\
\hline & $0.8 \mathrm{D}_{\mathrm{TM}}-\mathrm{WO}$ damper & 0.28 & 0.45 & 0.37 & 0.45 \\
\hline & $0.8 \mathrm{D}_{\mathrm{TM}}$-Passive & 0.34 & 0.46 & 0.54 & 0.46 \\
\hline & $0.8 \mathrm{D}_{\mathrm{TM}-\mathrm{IT} 1 \mathrm{FS}}$ & 0.39 & 0.44 & 0.62 & 0.44 \\
\hline & $0.8 \mathrm{D}_{\mathrm{TM}}-\mathrm{IT} 2 \mathrm{FS}+\mathrm{RZF}$ & 0.41 & 0.44 & 0.65 & 0.44 \\
\hline \multirow[t]{5}{*}{ Acceleration } & $1.0 \mathrm{D}_{\mathrm{TM}}-\mathrm{WO}$ damper & 0.29 & 0.43 & 0.50 & 0.43 \\
\hline & $0.8 \mathrm{D}_{\mathrm{TM}}-\mathrm{WO}$ damper & 0.24 & 0.43 & 0.33 & 0.43 \\
\hline & $0.8 \mathrm{D}_{\mathrm{TM}}$-Passive & 0.27 & 0.48 & 0.47 & 0.48 \\
\hline & $0.8 \mathrm{D}_{\mathrm{TM}-\mathrm{IT} 1 \mathrm{FS}}$ & 0.34 & 0.47 & 0.61 & 0.47 \\
\hline & $0.8 \mathrm{D}_{\mathrm{TM}}-\mathrm{IT} 2 \mathrm{FS}+\mathrm{RZF}$ & 0.36 & 0.46 & 0.67 & 0.46 \\
\hline
\end{tabular}

According to ASCE 7-22, the collapse probability at MCE intensity shall be lower by $10 \%$ for the average of events. The diagrams show that the presence of moat walls at total maximum design displacement, according to ASCE7-22, results in an unsatisfactory collapse risk in the case of acceleration damage measure but still is acceptable in the case of drift. However, putting moat walls at $0.8 \mathrm{D}_{\mathrm{TM}}$ in the model without damper results in increasing collapse probability more than $10 \%$ at MCE level in both damage measures. Using semi-active control systems improved the probability of collapse in both damage measures and putting values in an acceptable range in both distances. At both damage states, the proposed controller performed better than the IT1FS controller. In contrast, the passive controller with a constant voltage system increased the probability of failure in Acceleration, even compared to structures without dampers.

The probability density function (PDF) diagrams of base-isolated displacement can give a suitable comparative view for evaluating the ability of considered systems to reduce lateral movement demand. In this regard, PDFs of isolated level displacement are calculated without considering the presence of moat walls. Given that the analysis is performed in two directions, the lognormal joint distribution for two variables is expressed by a bivariate lognormal distribution. The following equations are used to express the probability density function of the bivariate lognormal distribution (Klein, 1957).

$$
\begin{aligned}
& f\left(u_{1}, u_{2}\right)=\frac{1}{2 \pi u_{1} u_{2} \sigma_{U_{1}} \sigma_{U_{2}} \sqrt{1-\rho^{2}}} \exp \left(-\frac{P}{2}\right) \\
& P=\frac{1}{1-\rho^{2}}\left[\left(\frac{\ln u_{1}-\mu_{U_{1}}}{\sigma_{U_{1}}}\right)^{2}-2 \rho\left(\frac{\ln u_{1}-\mu_{U_{1}}}{\sigma_{U_{1}}}\right)\left(\frac{\ln u_{2}-\mu_{U_{2}}}{\sigma_{U_{2}}}\right)+\left(\frac{\ln u_{2}-\mu_{U_{2}}}{\sigma_{U_{2}}}\right)^{2}\right]
\end{aligned}
$$

where $\rho$ is the correlation coefficient and $\mu_{U}$ and $\sigma_{U}$ are the mean and standard deviations, respectively. Here, the parameters $\mathrm{u}_{1}$ and $\mathrm{u}_{2}$ are structure responses in two primary directions. Figure 16 shows the lognormal probability density function diagrams for isolation level displacement for different cases. 
The given results imply that the structure with no damper has the highest mean and scatter for the isolation level displacement. The mean base displacement is decreased by $35 \%$ in the case of using the proposed control system compared to the uncontrolled isolated structure. Almost the same is true for the case of passive controller compared to the uncontrolled structure. The reductions in mean base-displacements are $41 \%$ and $28 \%$ for the cases with passive and IT1FS controllers, respectively. Although the mean value of the base-movement in the passive controller is slightly lower than those in the semi-active controller systems, the responses of the superstructure are increased. The isolated structure with the proposed fuzzy control system has the lowest scatter for isolation level displacement.

According to Eq. (1), the expected damage costs of structures are obtained and shown in Figure 17. These costs are included the cost of supplementary energy dissipation. The proposed controller system reduces the total expected damage cost by $31 \%$ and $13 \%$ compared to the structure with passive and type 1 fuzzy controller, which in turn leads to $64 \%$ lower damage cost than the isolated structure without a damper system in the presence of moat wall at the distance of $0.8 \mathrm{D}_{\mathrm{TM}}$. In cases without additional damping systems, the possible damage cost has increased more than 1.8 times by reducing the distance of moat walls from $1.0 \mathrm{D}_{\mathrm{TM}}$ to $0.8 \mathrm{D}_{\mathrm{TM}}$.

\section{Concluding remarks}

This study assesses the seismic probability and LCC of structures equipped with passive and smart hybrid isolation systems considering the risk of pounding to the moat walls under long-pulse type seismic records. MR dampers are used at the base level in the Hybrid isolation system as an adaptive dissipation energy device, with a modified interval Type-2 fuzzy logic controller. The Type-2 fuzzy-based controller system is being developed with the Red-Zone function as a decision-maker in order to increase the controller's ability to avoid the potential pounding. The membership function parameters are identified through genetic algorithm optimization to minimize the superstructure responses. Structures fragility curves are calculated using IDA analysis, and probable damage costs are estimated according to the probability damage exceedance thresholds. Pounding forces strongly affect the uncontrolled structure so that in the case of $0.8 \mathrm{D}_{\mathrm{TM}}$, the mean values of Acceleration and Drift are increased $89 \%$ and $340 \%$. Interestingly, $84 \%$ value of base-level acceleration increased about six times in this case.

The collapse probability of the isolated structures with the code-based gap distance exceeds the ASCE 7-22 acceptable value. However, the proposed controller of IT2FS+RZF puts the structure's collapse probability within an acceptable range. This system has a lower damage cost and performs better performance compared to IT1FS and passive controller. Based on the bivariate probability density function, the optimized proposed controller can reduce the scatter and mean of the base displacement. It is also found that there is a possibility of increasing superstructure responses in the case of using the passive controller compared to the uncontrolled isolated structures, which leads to an increase in damage cost. These results emphasize the importance of gap size distance on the isolated structures' collapse probability and damage cost. It is identified that an increase in the code-based free moving space around the isolated structure is necessary, and the proposed 
control system can be used in existing isolated structures without sufficient gap size to have an acceptable collapse probability.

\section{Declaration of Conflicting Interests}

The authors declared no conflicting interest with respect to the research, authorship, and/or publication of this paper.

\section{Funding}

The authors received no financial support for the research, authorship, and/or publication of this article 


\section{References:}

(2015) MATLAB and Statistics Toolbox Release 2015b. Natick, Massachusetts, United States: The MathWorks, Inc., Natick, Massachusetts, United States.

Agency. FEM. (1992). A benefit-cost model for the seismic rehabilitation of buildings.

Alam MS, Bhuiyan MR and Billah AM. (2012) Seismic fragility assessment of SMA-bar restrained multispan continuous highway bridge isolated by different laminated rubber bearings in medium to strong seismic risk zones. Bulletin of Earthquake Engineering 10: 1885-1909.

American Society of Civil Engineers. (2016) Minimum design loads and associated criteria for buildings and other structures (ASCE/SEI 7-16).

American Society of Civil Engineers. (2021) Minimum Design Loads and Associated Criteria for Buildings and Other Structures (ASCE/SEI 7-22).

Anajafi H, Poursadr K, Roohi M, et al. (2020) Effectiveness of seismic isolation for long-period structures subject to far-field and near-field excitations. Frontiers in Built Environment 6: 24.

ANSI A. (2016) AISC 360-16. Specification for structural steel buildings.

Bathaei A, Zahrai SM and Ramezani M. (2018) Semi-active seismic control of an 11-DOF building model with TMD+ MR damper using type-1 and-2 fuzzy algorithms. Journal of Vibration and Control 24: 2938-2953.

Bhagat S, Wijeyewickrema AC and Subedi N. (2021) Influence of near-fault ground motions with flingstep and forward-directivity characteristics on seismic response of base-isolated buildings. Journal of Earthquake Engineering 25: 455-474.

Bhandari M, Bharti S, Shrimali M, et al. (2019) Seismic fragility analysis of base-isolated building frames excited by near-and far-field earthquakes. Journal of Performance of Constructed Facilities 33: 04019029.

Castaldo P, Palazzo B and Della Vecchia P. (2016) Life-cycle cost and seismic reliability analysis of 3D systems equipped with FPS for different isolation degrees. Engineering Structures 125: 349-363.

Chan RW, Lin Y-S and Tagawa H. (2019) A smart mechatronic base isolation system using earthquake early warning. Soil Dynamics and Earthquake Engineering 119: 299-307.

Choi KM, Cho SW, Jung HJ, et al. (2004) Semi-active fuzzy control for seismic response reduction using magnetorheological dampers. Earthquake engineering \& structural dynamics 33: 723-736.

Council AT. (1985) ATC-13. Applied Technology Council Redwood City, California, 492.

Council AT. (2009) Quantification of building seismic performance factors: US Department of Homeland Security, FEMA.

Dumne S, Shrimali M and Bharti S. (2017) Earthquake performance of hybrid controls for coupled buildings with MR dampers and sliding base isolation. Asian J. Civ. Eng 18: 63-97.

Ehrgott M. (2008) Multiobjective Optimization. AI Magazine 29: 47.

El-Khoury O, Kim C, Shafieezadeh A, et al. (2018) Mitigation of the seismic response of multi-span bridges using MR dampers: Experimental study of a new SMC-based controller. Journal of vibration and control 24: 83-99.

Elenas A and Meskouris K. (2001) Correlation study between seismic acceleration parameters and damage indices of structures. Engineering Structures 23: 698-704.

Ellingwood BR and Kinali K. (2009) Quantifying and communicating uncertainty in seismic risk assessment. Structural Safety 31: 179-187.

FEMA N. (2003) Multi-hazard loss estimation methodology, earthquake model (HAZUS-MH MR4).

Gong W and Xiong S. (2016) Probabilistic seismic risk assessment of modified pseudo-negative stiffness control of a base-isolated building. Structure and Infrastructure Engineering 12: 1295-1309.

Güneş N and Ulucan ZÇ. (2021) Collapse probability of code-based design of a seismically isolated reinforced concrete building. Structures. Elsevier, 2402-2412.

Hayes Jr JR, McCabe SL and Mahoney M. ICSSC Recommended Practice (RP) 9 Implementation Guidelines for Executive Order 13717: Establishing a Federal Earthquake Risk Management Standard. 
Ismail M, Ikhouane F and Rodellar J. (2009) The hysteresis Bouc-Wen model, a survey. Archives of Computational Methods in Engineering 16: 161-188.

Khansefid A and Bakhshi A. (2019) Advanced two-step integrated optimization of actively controlled nonlinear structure under mainshock-aftershock sequences. Journal of Vibration and Control 25: 748-762.

Kikuchi M, Aiken I and Kasalanati A. (2012) Simulation analysis for the ultimate behavior of full-scale lead-rubber seismic isolation bearings. 15th World Conference on Earthquake Engineering. 24.

Kitayama S and Constantinou MC. (2018) Collapse performance of seismically isolated buildings designed by the procedures of ASCE/SEI 7. Engineering Structures 164: 243-258.

Kitayama S and Constantinou MC. (2019) Effect of displacement restraint on the collapse performance of seismically isolated buildings. Bulletin of Earthquake Engineering 17: 2767-2786.

Klein L. (1957) The Lognormal Distribution. JSTOR.

Mansouri I, Ghodrati Amiri G, Hu JW, et al. (2017) Seismic fragility estimates of LRB base isolated frames using performance-based design. Shock and Vibration 2017.

Massumi A, Sadeghi K and Ghojoghi O. (2021) Effect of Aftershock Characteristics on the Fragility Curve of Post-Mainshock RC Frames.

Mavronicola EA, Polycarpou PC and Komodromos P. (2017) Spatial seismic modeling of base-isolated buildings pounding against moat walls: effects of ground motion directionality and mass eccentricity. Earthquake engineering \& structural dynamics 46: 1161-1179.

Mazza F and Labernarda R. (2020) Magnetic damped links to reduce internal seismic pounding in baseisolated buildings. Bulletin of Earthquake Engineering 18: 6795-6824.

McKenna F, Fenves G and Scott M. (2006) Computer program OpenSees: open system for earthquake engineering simulation. UC Berkeley.

Mitropoulou CC, Lagaros ND and Papadrakakis M. (2011) Life-cycle cost assessment of optimally designed reinforced concrete buildings under seismic actions. Reliability Engineering \& System Safety 96: 1311-1331.

NourEldin M, Naeem A and Kim J. (2019) Life-cycle cost evaluation of steel structures retrofitted with steel slit damper and shape memory alloy-based hybrid damper. Advances in Structural Engineering 22: 3-16.

Pant DR and Wijeyewickrema AC. (2012) Structural performance of a base-isolated reinforced concrete building subjected to seismic pounding. Earthquake engineering \& structural dynamics 41: 17091716.

Providakis C. (2008) Effect of LRB isolators and supplemental viscous dampers on seismic isolated buildings under near-fault excitations. Engineering Structures 30: 1187-1198.

Rayegani A. (2014) The effect of arrangement of viscoelastic dampers in the performance of steel structures using Incremental Dynamic Analysis. Sharif University of Technology: Sharif University of Technology.

Rayegani A and Nouri G. (2020) Application of Smart Dampers for Prevention of Seismic Pounding in Isolated Structures Subjected to Near-fault Earthquakes. Journal of Earthquake Engineering: 1-16.

Shao B and Mahin SA. (2020) A probabilistic design method to achieve targeted levels of reliability for seismically isolated structures. Earthquake Spectra 36: 741-766.

Shariatmadar H, Golnargesi S and Akbarzadeh T. (2014) Vibration control of buildings using ATMD against earthquake excitations through interval type-2 fuzzy logic controller.

Sheikh M, Xiong J and Li W. (2012) Reduction of seismic pounding effects of base-isolated RC highway bridges using MR damper. Structural Engineering and Mechanics 41: 791-803.

Shirazian S, Ghayamghamian M and Nouri G. (2011) Developing of fragility curve for two-span simply supported concrete bridge in near-fault area. World Acad Sci Eng Technol 51: 571-575.

Shrimali M, Bharti S and Dumne S. (2015) Seismic response analysis of coupled building involving MR damper and elastomeric base isolation. Ain Shams Engineering Journal 6: 457-470.

Sobhi P and Far H. (2021) Impact of structural pounding on structural behaviour of adjacent buildings considering dynamic soil-structure interaction. Bulletin of Earthquake Engineering: 1-33. 
Vamvatsikos D and Cornell CA. (2002) Incremental dynamic analysis. Earthquake engineering \& structural dynamics 31: 491-514.

Wen Y-K and Kang Y. (2001) Minimum building life-cycle cost design criteria. I: Methodology. Journal of Structural Engineering 127: 330-337.

Wolff E, Ipek C, Constantinou M, et al. (2015) Effect of viscous damping devices on the response of seismically isolated structures. Earthquake Engineering \& Structural Dynamics 44: 185-198.

Yan X, Xu Z-D and Shi Q-X. (2020) Fuzzy neural network control algorithm for asymmetric building structure with active tuned mass damper. Journal of Vibration and Control: 1077546320910003.

Yang G, Spencer Jr BF, Jung H-J, et al. (2004) Dynamic modeling of large-scale magnetorheological damper systems for civil engineering applications. Journal of Engineering Mechanics 130: 1107 1114. 

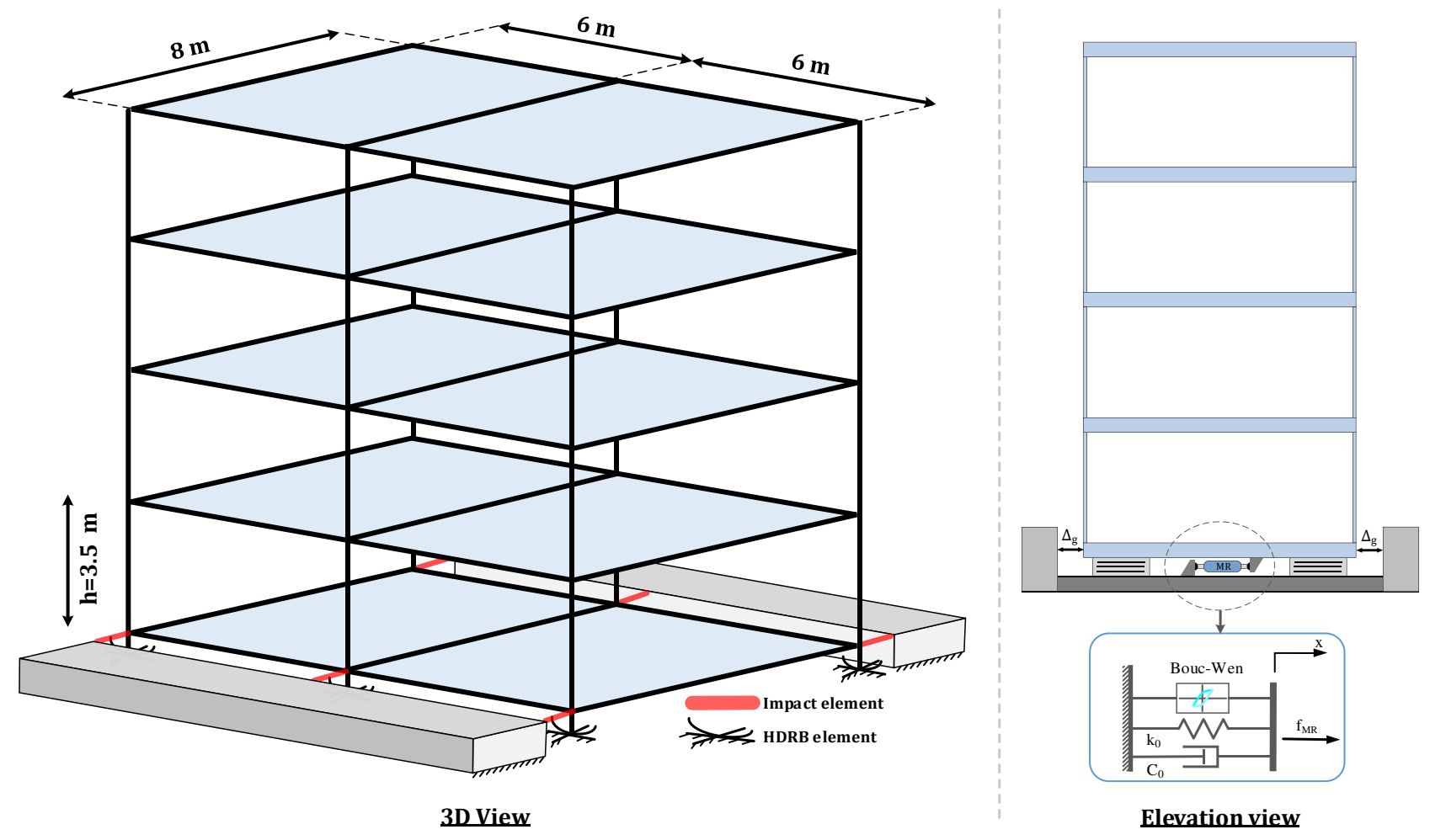

Figure 1. Smart base-isolated four-story building and Bouc Wen model scheme 


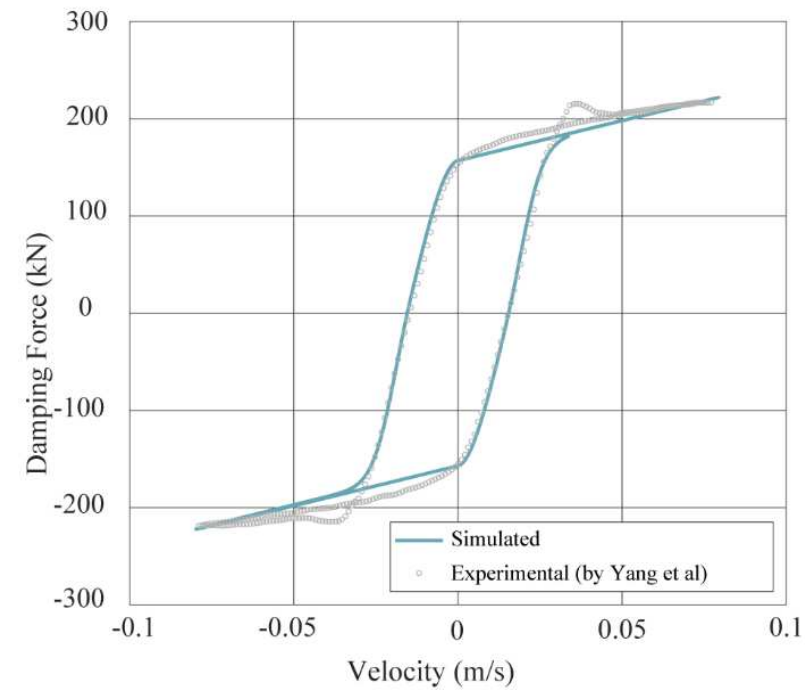

(a)

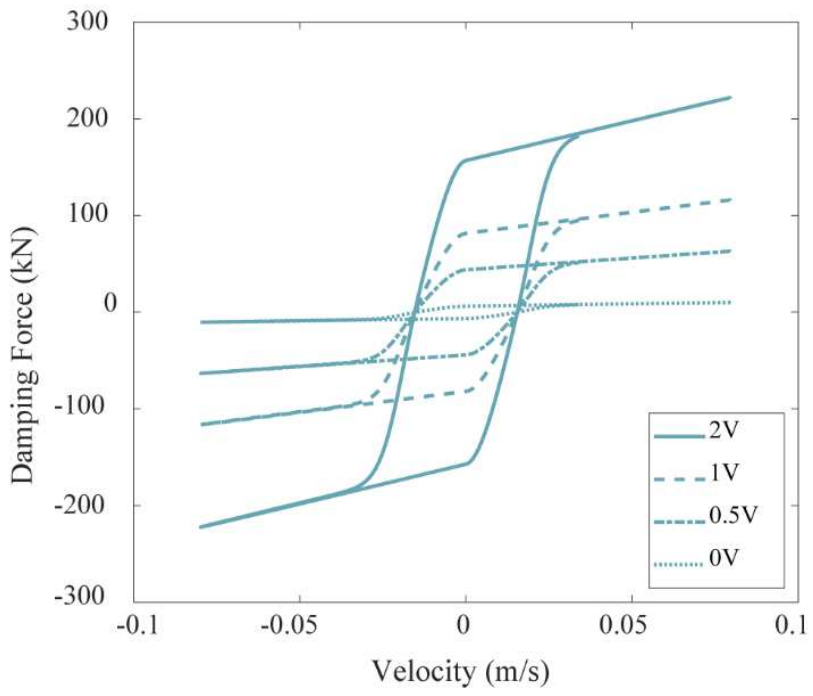

(b)

Figure 2. (a) Comparison between the evaluated force-velocity diagram of the MR damper and the experimental results under the input voltage of $2 \mathrm{~V}$, and (b) evaluated force-velocity diagram of the MR damper under different input voltages 


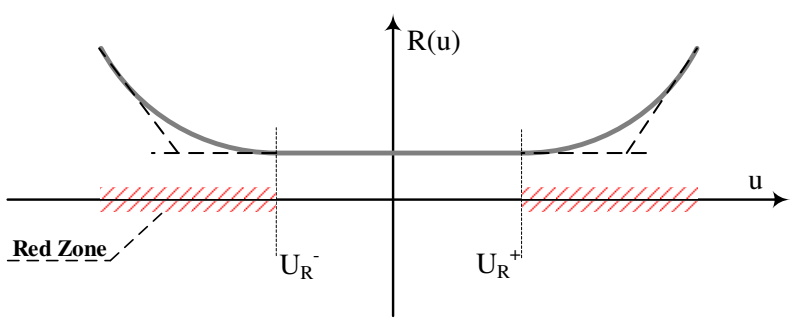

Figure 3. Red-zone function $(\rho=1)$ 


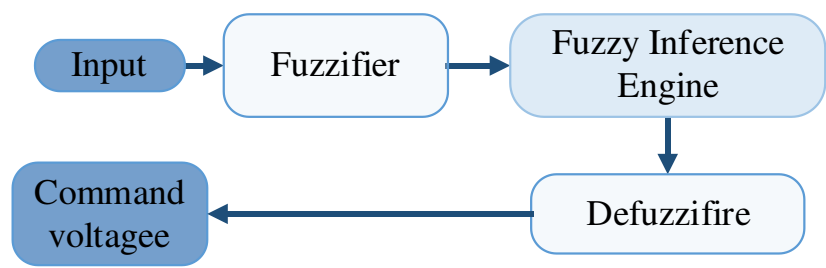

Figure 4. The layout of the Type-1 FLC 


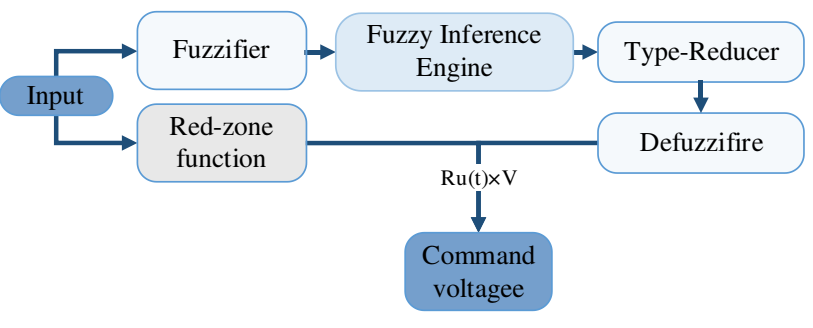

Figure 5. The layout of the Type-2 FLC with red-zone function 


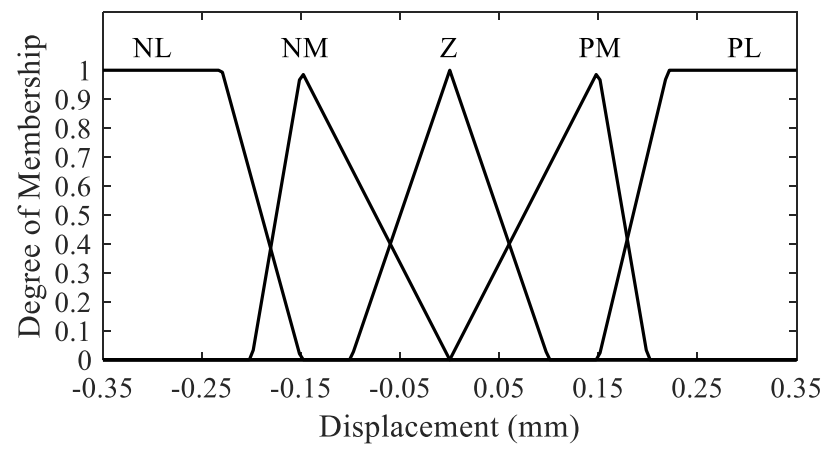

Figure 6. Membership function of Type-1 FLC for input variable (displacement) 


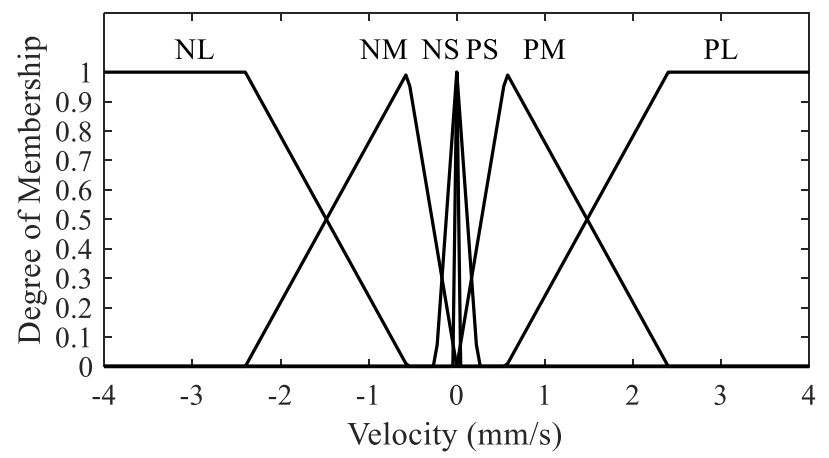

Figure 7. Membership function of Type-1 FLC for input variable (Velocity) 


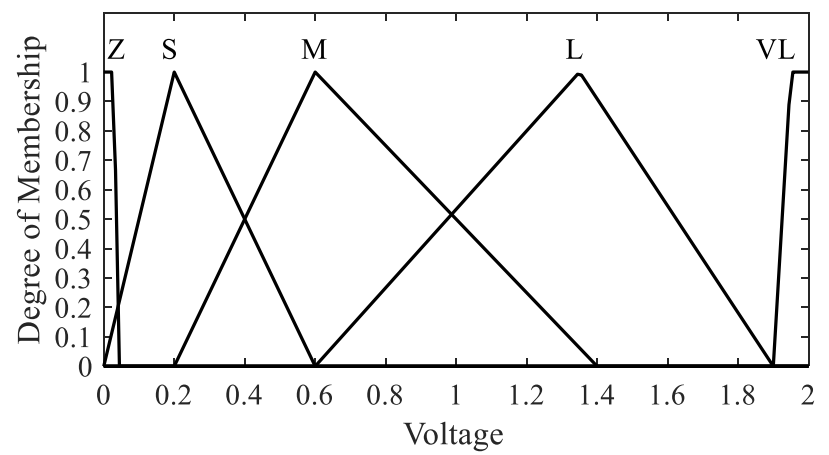

Figure 8. Membership function of Type-1 FLC for output variable (Voltage) 

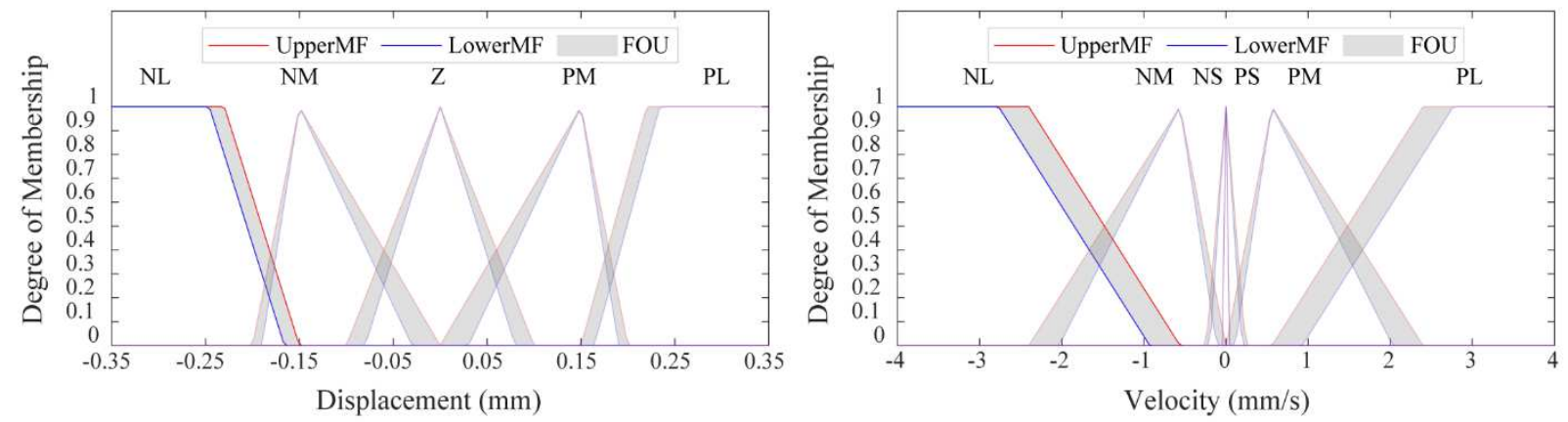

Figure 9. Membership function of Type-2 FLC for input variables 

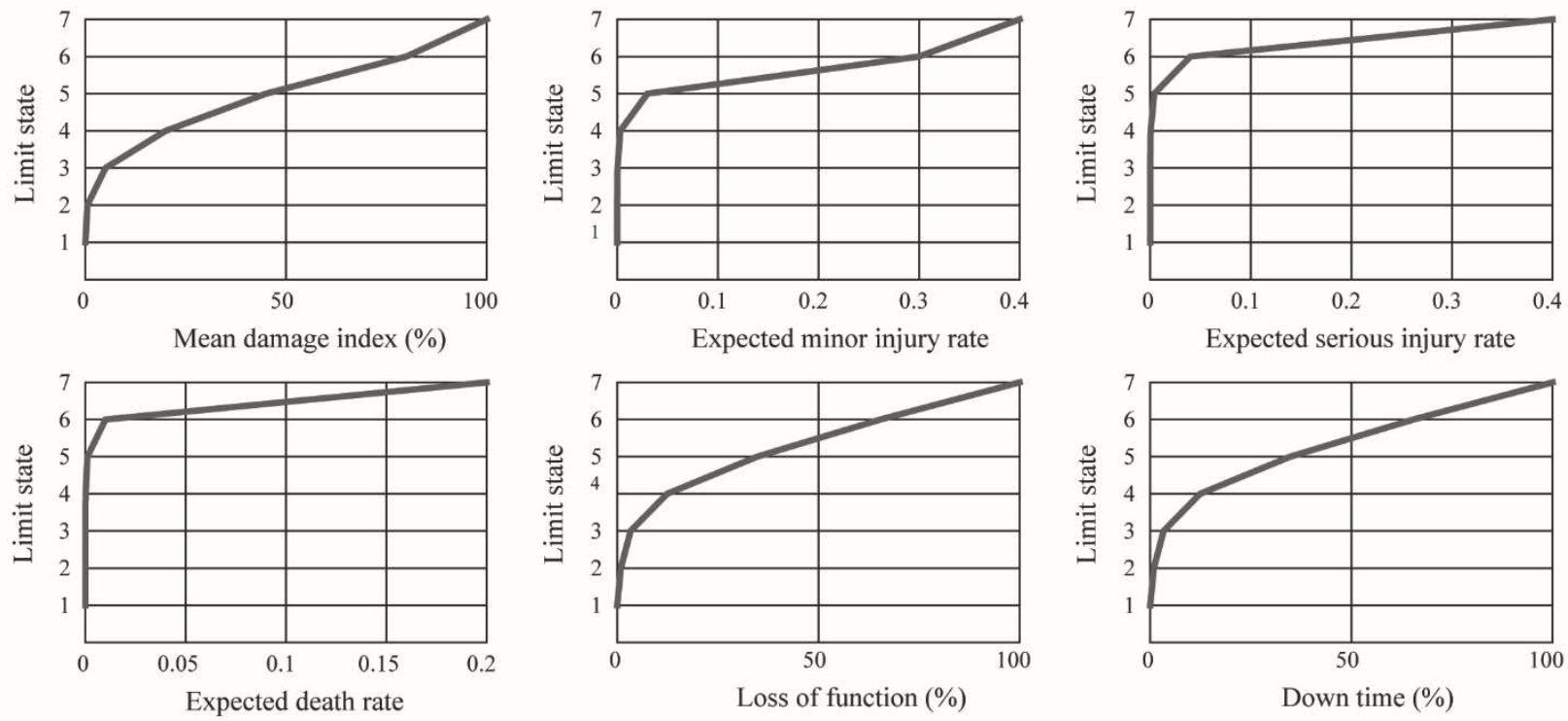

Figure 10. Damage state costs calculation parameters 

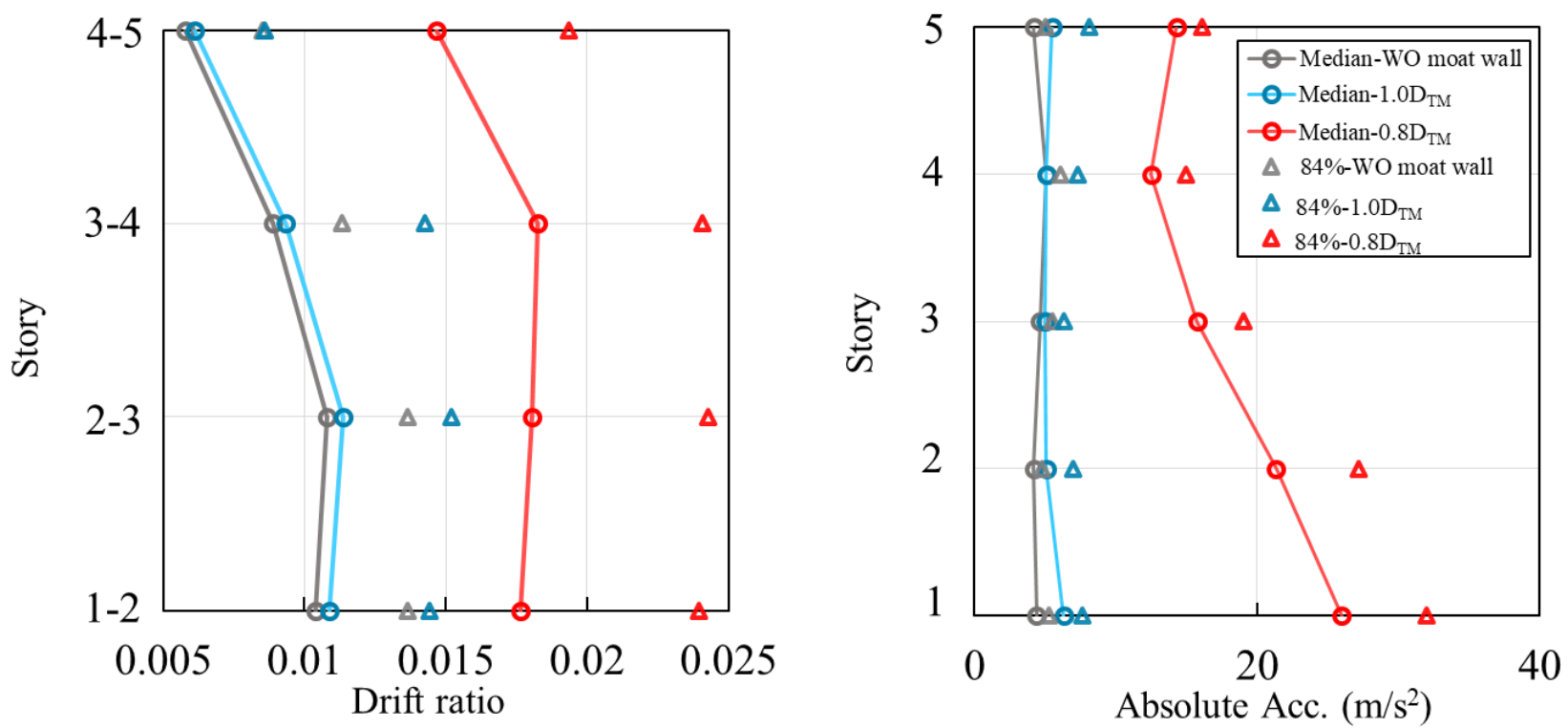

Figure 11. median and 84\% of Drift and Acceleration of the isolated structure 


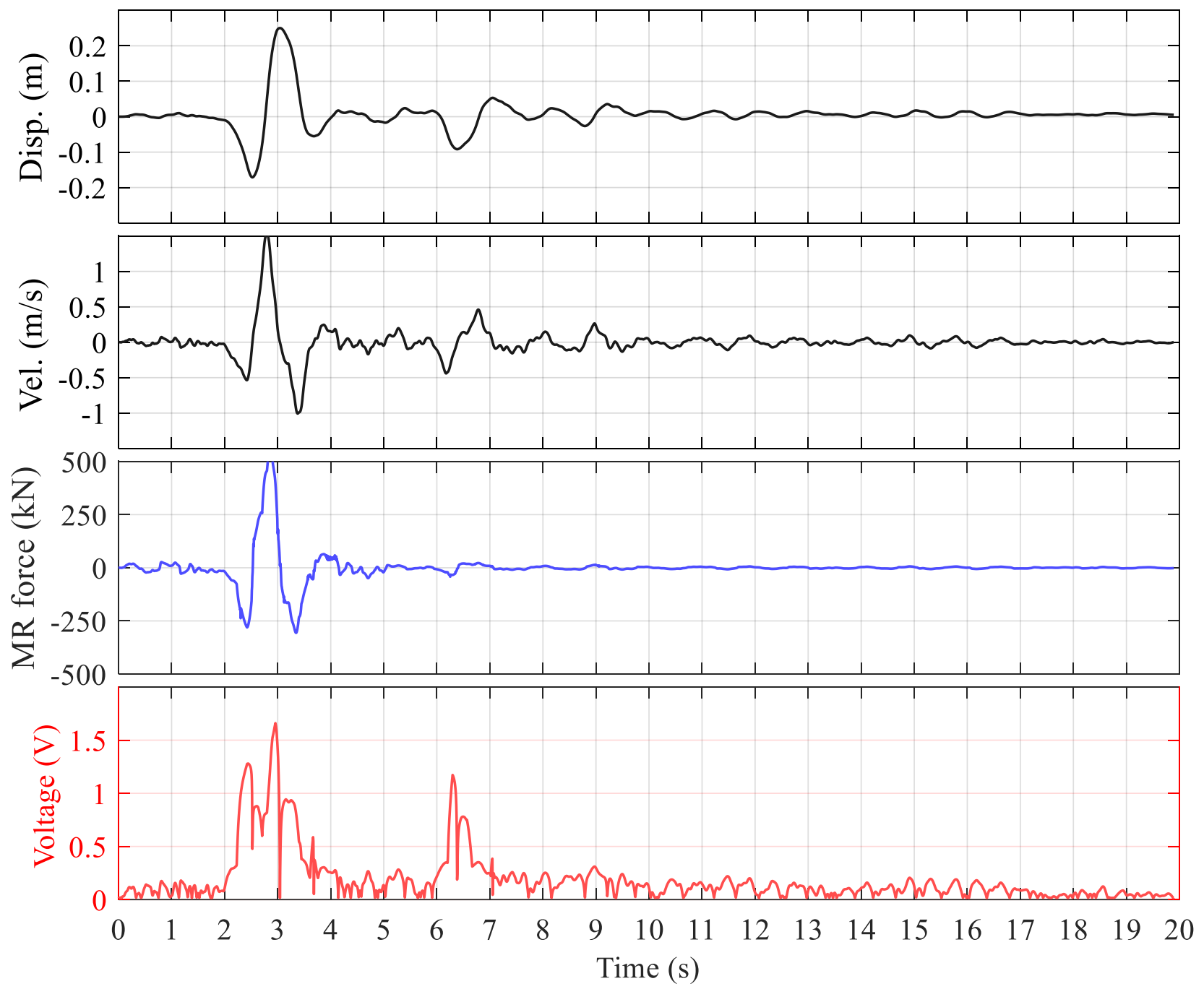

Figure 12. Diagram of MR damper responses and command voltage under Northridge earthquake (NGA=1063) 


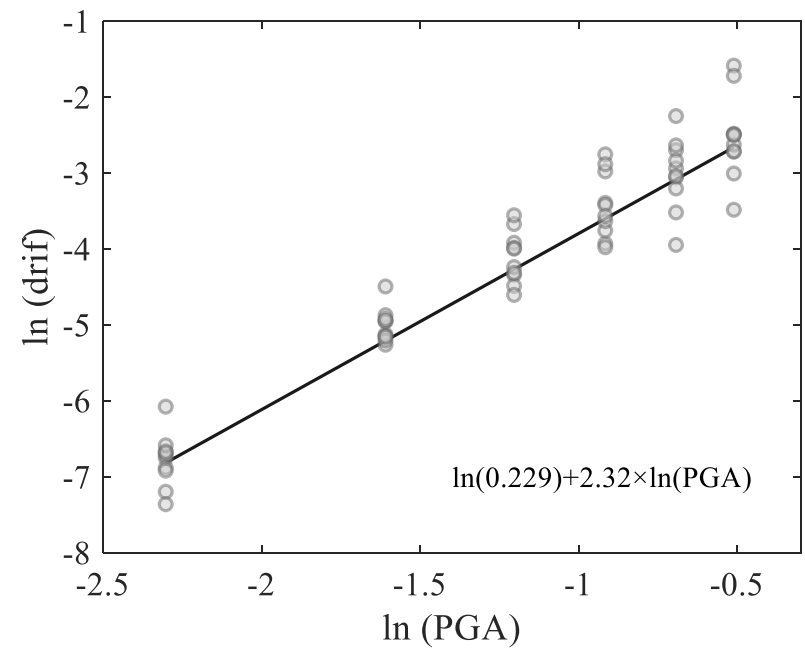

Figure 13. Drift PSDM for "1.0D $\mathrm{D}_{\mathrm{TM}}-\mathrm{WO}$ damper" model 


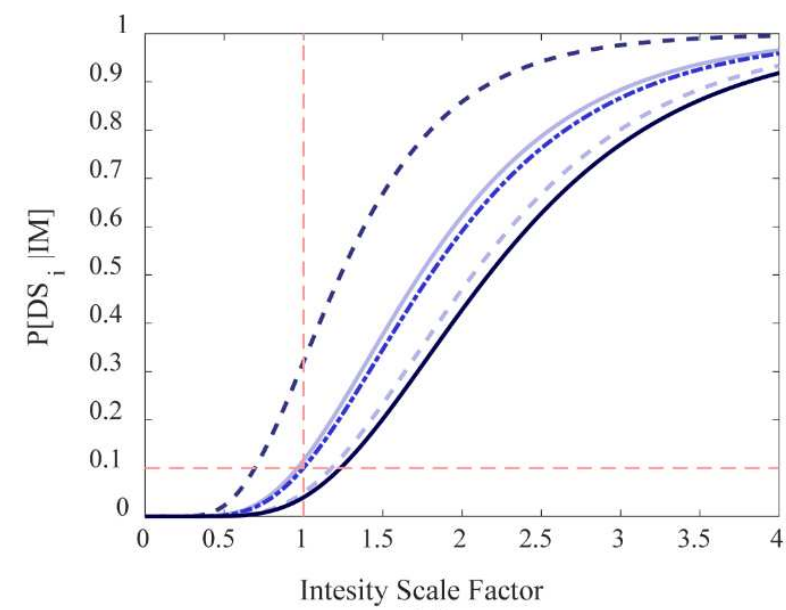

(a)

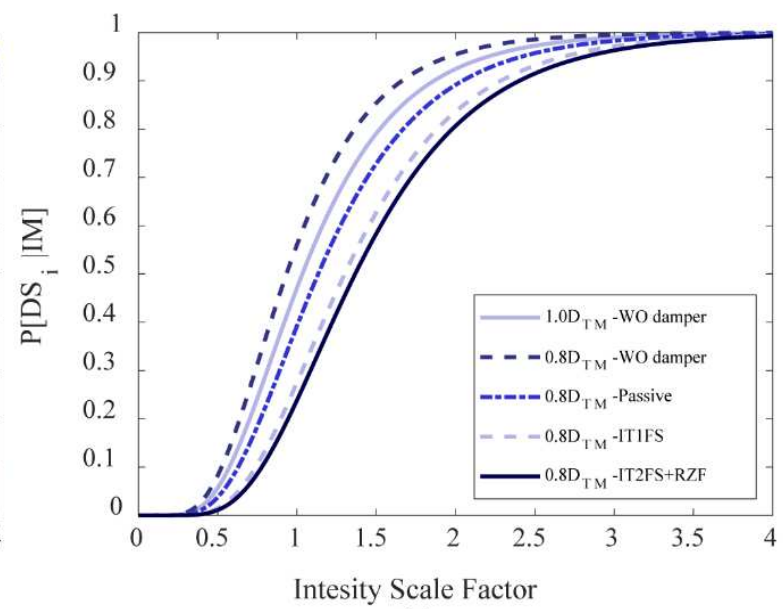

(b)

Figure 14. Comparison of exceedance probability curves of Drift damage state of a) collapse, and b) moderate 


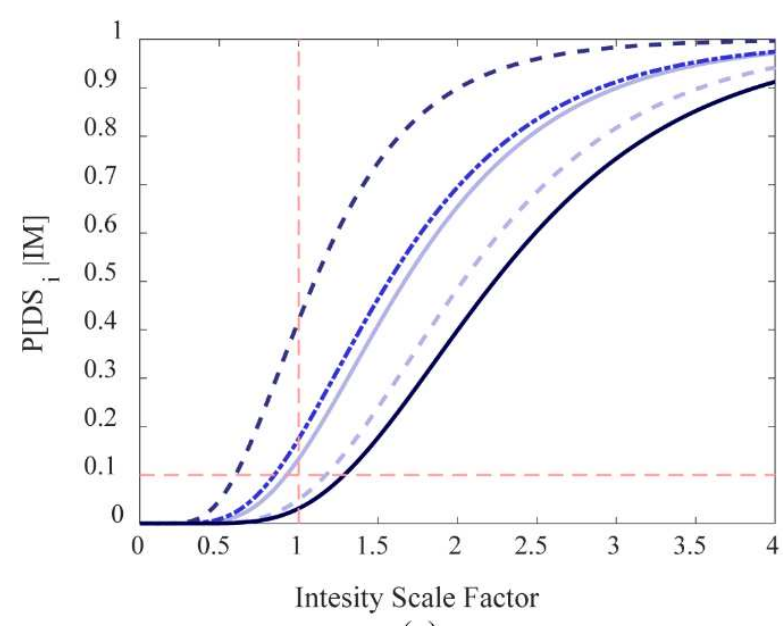

(a)

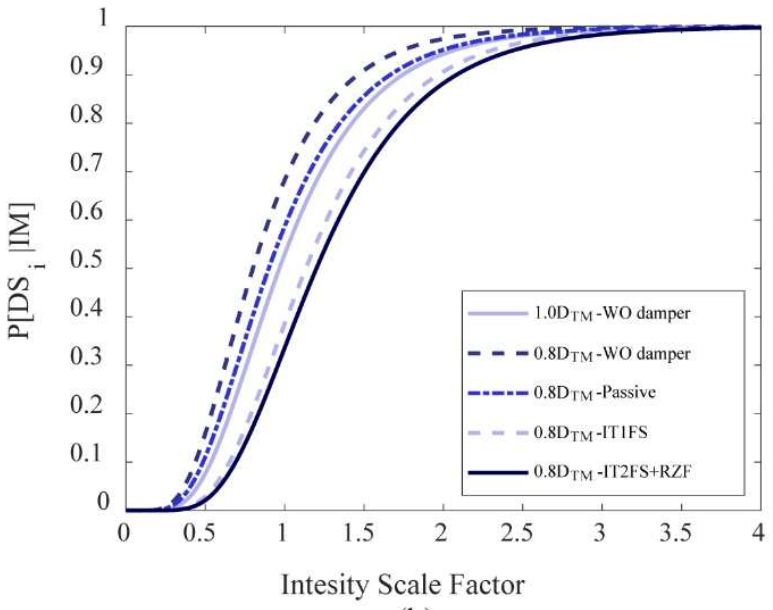

(b)

Figure 15. Comparison of exceedance probability curves of acceleration damage state of a) collapse, and b) moderate 


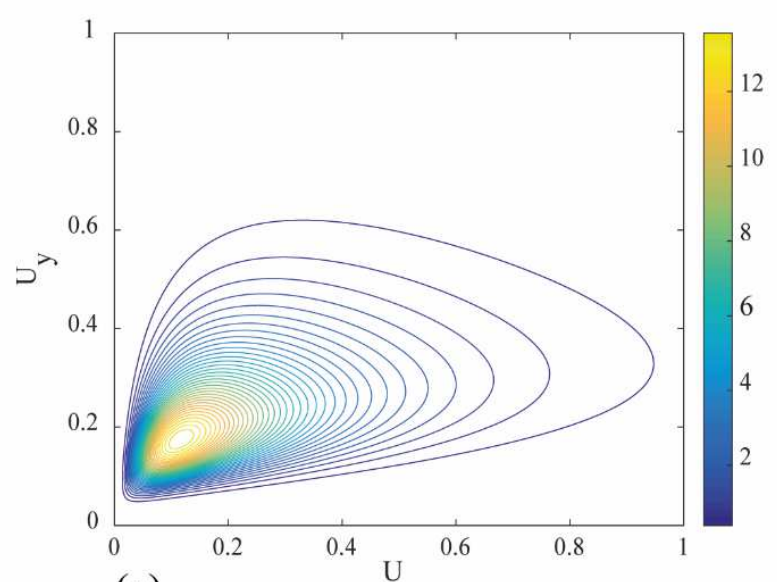

(a)

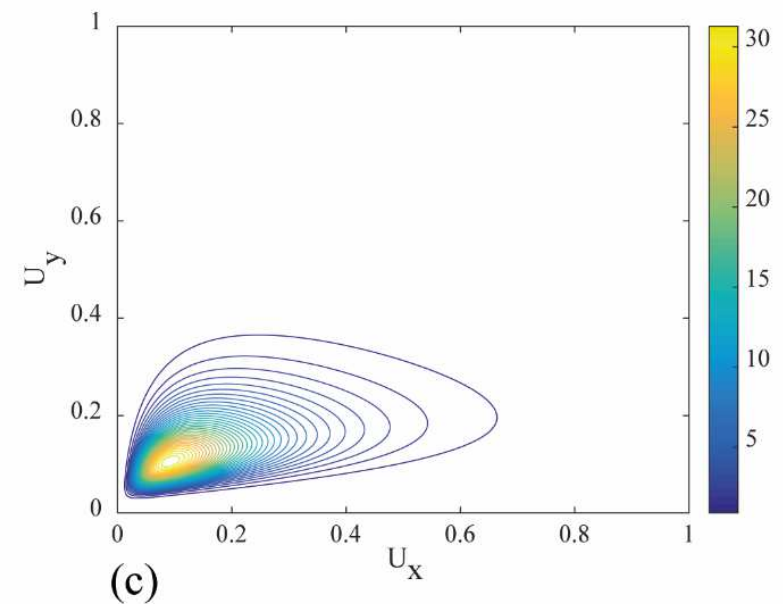

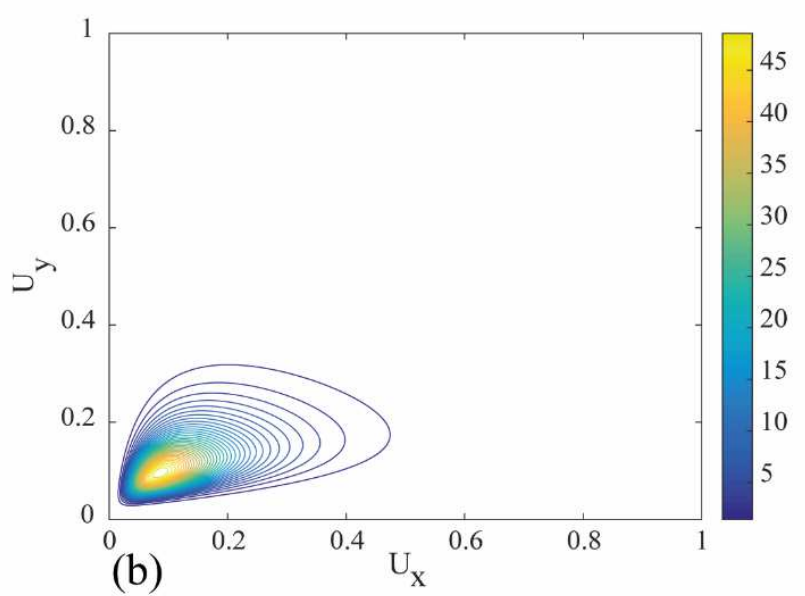

(b)

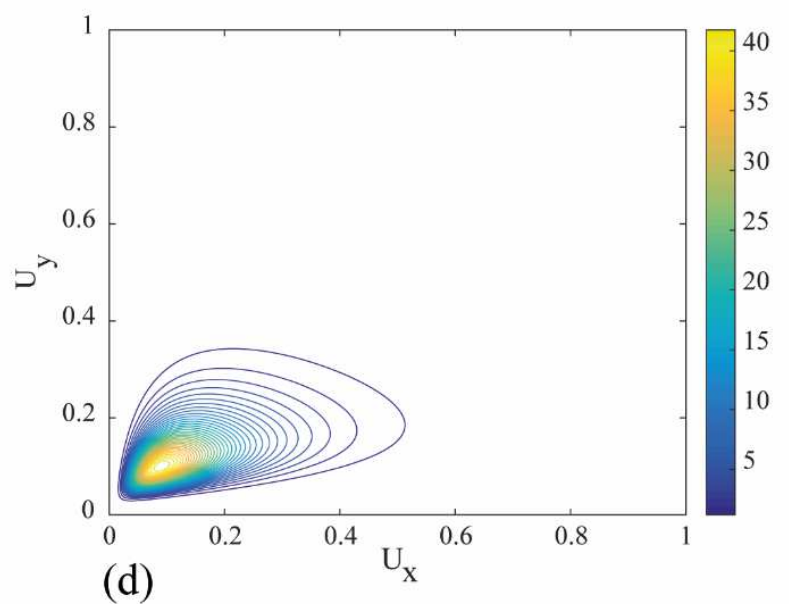

Figure 16. Bivariate lognormal probability density functions of base-displacement for cases of a) Without additional damping, b) Passive controller, c) IT1FS controller, and d) IT2FS+RZF controller 


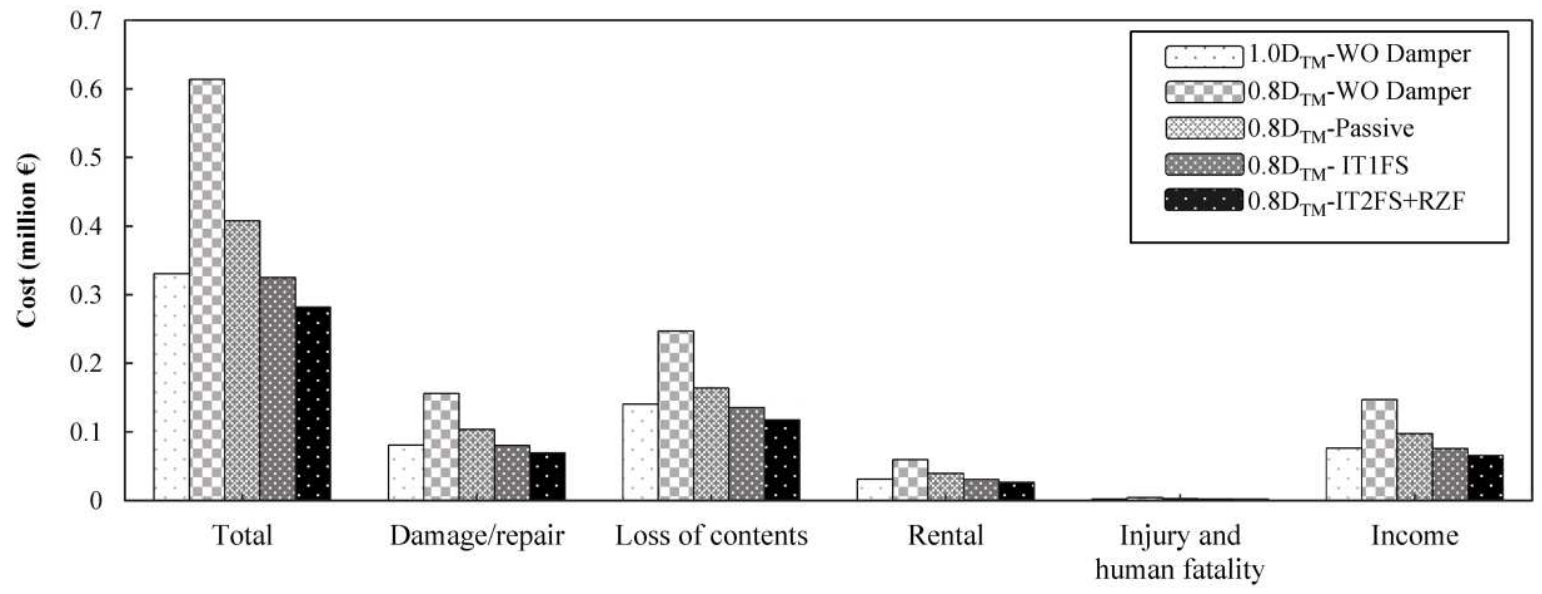

Figure 17. Damage cost of considered cases 